\title{
Comparison of perennial and preseasonal allergoid immunotherapy in grass pollen allergic patients
}

\author{
Zeynep Celebi Sözener, ${ }^{1}$ Dilşad Mungan, ${ }^{1}$ Ömür Aydın, ${ }^{1}$ Derya Seçil, ${ }^{1}$ Münevver Nur Pınar, ${ }^{2}$ \\ Yavuz Selim Demirel, ${ }^{1}$ Betul Ayşe Sin ${ }^{1}$
}

\begin{abstract}
Background: The clinical and immunological efficacy of preseasonal allergoid immunotherapy has been previously investigated, however, studies comparing the effectiveness of the two protocols are limited in the literature.

Objective: The aim of this study is to compare the clinical and immunological efficacy of pre-seasonal and perennial allergoid immunotherapy.

Methods: This is a prospective cross sectional two-arm study. During the season; symptom and medication scores were filled. Before and at the end of the season; RQLQ was applied, Phl $p$ sIgE, sIgG4 and IL-10 levels were measured.

Results: In preseasonal group patients had better symptom control for most of the weeks, particularly during the peak pollen period (April: $\mathrm{w}-2 \& \mathrm{w}-4, p=0.04$; May: $\mathrm{w}-2, p=0.02$; June: $\mathrm{w}-1, \mathrm{w}-2, p=0.02 ; \mathrm{w}-3, \mathrm{w}-5, p=0.03$; July: $\mathrm{w}-2, p=0.01 ; \mathrm{w}-3, p=0.02 ; \mathrm{w}-4, p=0.04)$. In the perennial group, sIgG4 [1 $1^{\text {st }}$ time point: preseasonal $0.02 \mathrm{mg}_{\mathrm{A}} / \mathrm{L}$ vs perennial $0.13 \mathrm{mg}_{\mathrm{A}} / \mathrm{L}(p<0.0001) ; 2^{\text {nd }}$ time point: preseasonal $0.52 \mathrm{mg}_{\mathrm{A}} / \mathrm{L}$ vs perennial $0.33 \mathrm{mg}_{\mathrm{A}} / \mathrm{L} ; 3^{\text {rd }}$ time point: preseasonal $0.04 \mathrm{mg}_{\mathrm{A}} / \mathrm{L}$ vs perennial $\left.0.12 \mathrm{mg}_{\mathrm{A}} / \mathrm{L}(p<0.0001)\right]$ and $\mathrm{IL}-10$ ( $1^{\text {st }}$ time point: preseasonal $1.45 \mathrm{pg} / \mathrm{ml}$ vs perennial $2.03 \mathrm{pg} / \mathrm{ml} ; 2^{\text {nd }}$ time point: preseasonal $2.29 \mathrm{pg} / \mathrm{ml}$ vs perennial $2.19 \mathrm{pg} / \mathrm{ml} ; 3^{\text {rd }}$ time point: preseasonal $2.32 \mathrm{pg} / \mathrm{ml}$ vs perennial $2.16 \mathrm{pg} / \mathrm{ml}$ ) levels were higher and more stable.
\end{abstract}

Conclusion: Preseasonal immunotherapy provided better control of symptoms throughout the pollen season. However, the blocking antibody response was stronger and more permanent in the perennial immunotherapy group.

Key words: SCIT, preseasonal, perennial, IgE, IgG4, IL-10, symptom scores, RQLQ

\section{Citation:}

Sözener, Z. C., Mungan, D., Aydın, Ö., Seçil, D., Pınar, M. N., Demirel, Y. S., Sin, B. A. (2023) Comparison of perennial and preseasonal allergoid immunotherapy in grass pollen allergic patients. Asian Pac J Allergy Immunol, 41(1), 20-29. https://doi.org/10.12932/ap-280121-1048

\section{Affiliations:}

1 Ankara University School of Medicine Department of Chest diseases Division of Immunology and Allergy, Ankara, Turkey

2 Ankara University Faculty of Science, Department of Biology, Ankara, Turkey

\section{Corresponding author:}

Dilşad Mungan

Ankara University School of Medicine, Department of Chest Diseases

Division of Immunology and Allergy, Ankara, TURKEY

E-mail: dilsadmungan@gmail.com

$\begin{array}{ll}\text { Abbrevations: } \\ \text { AIT } & \text { Allergen immunotherapy } \\ \text { Bregs } & \text { B regulatuar cells } \\ \text { ELISA } & \text { Enzyme-linked immunosorbent assay } \\ \text { HDM } & \text { House dust mite } \\ \text { IgE } & \text { Immunoglobulin E } \\ \text { IL-10 } & \text { Interleukin-10 } \\ \text { Phl p } & \text { Phelium pratense } \\ \text { RQLQ } & \text { Rhinitis quality of life questionnaire } \\ \text { SCIT } & \text { Subcutaneous immunotherapy } \\ \text { sIgE } & \text { Specific immunoglobulin E } \\ \text { sIgG4 } & \text { Specific immunoglobulin G4 } \\ \text { Th2 } & \text { T helper-2 } \\ \text { Tregs } & \text { T regulatuar cells } \\ \mathrm{V}_{0} & \text { Visit } 0 \\ \mathrm{~V}_{7} & \text { Visit } 7 \\ \mathrm{~V}_{8} & \text { Visit } 8\end{array}$




\section{Introduction}

Allergen immunotherapy (AIT) is the only guideline-approved, curative treatment that might alter the natural course of IgE-mediated allergic respiratory disease. Using the right allergen in the appropriate indication, AIT can significanly reduce symptoms and medication use, improve patients' quality of life and its clinical effectiveness continues even years after discontinuation. ${ }^{1,2}$

The aim of AIT is to induce immune tolerance against specific allergens. ${ }^{3}$ To improve immunotherapy, new allergy vaccines have been developed, often known as allergoids, with reduced allergenicity while maintaining immunogenicity., The clinical benefits and safety of using allergoid vaccines in AIT strategies have been reported in various clinical studies. ${ }^{67}$ Immunological and clinical efficacy is expected to occur earlier with the use of allergoid immunotherapy. Thus, an increase in patient compliance is possible with fewer injections and shorter treatment period. ${ }^{8}$

Allergoid immunotherapy applied with seasonal allergens is a different program than traditional immunotherapy regimens, and can be performed with two different protocols; preseasonal or perennial. The clinical and immunological efficacy of preseasonal allergoid immunotherapy has been previously investigated. ${ }^{8-12}$ However there are limited studies comparing the effectiveness of preseasonal and perennial allergoid immunotherapy. ${ }^{13-16}$ Therefore, we aimed to compare the clinical and immunological efficacy of preseasonal and perennial allergoid SCIT.

\section{Material and Methods Study design}

This is a prospective cross-sectional two-arm study performed in 2018. Study protocol was approved by the Ethic Committee of Ankara University Faculty of Medicine with the approvel number: 03-155-18. One arm was the preseasonal and the second arm was the perennial immunotherapy groups. Three time points were determined for the measurements: at the beginning of preseasonal immunotherapy $\left(\mathrm{V}_{0}\right.$-before $1^{\text {st }}$ injection), at the end of the preseasonal immunotherapy $\left(\mathrm{V}_{7}\right.$-after $7^{\text {th }}$ injection) and at the end of the pollen season $\left(\mathrm{V}_{8}\right.$-September). In the perennial immunotherapy group, measurements were performed at the same time points. (Figure 1)

After signing informed-consent forms, all patients were asked to fill in symptom and medication scores in the pollen season between April 1 and August 31 and, were also asked to complete rhinitis quality of life questionnaire (RQLQ) during $\mathrm{V}_{7}$ and $\mathrm{V}_{8}$. Blood samples were taken from all patients in both arms at the three time points to measure $P h l p$ sIgE, sIgG4 and IL- 10 .

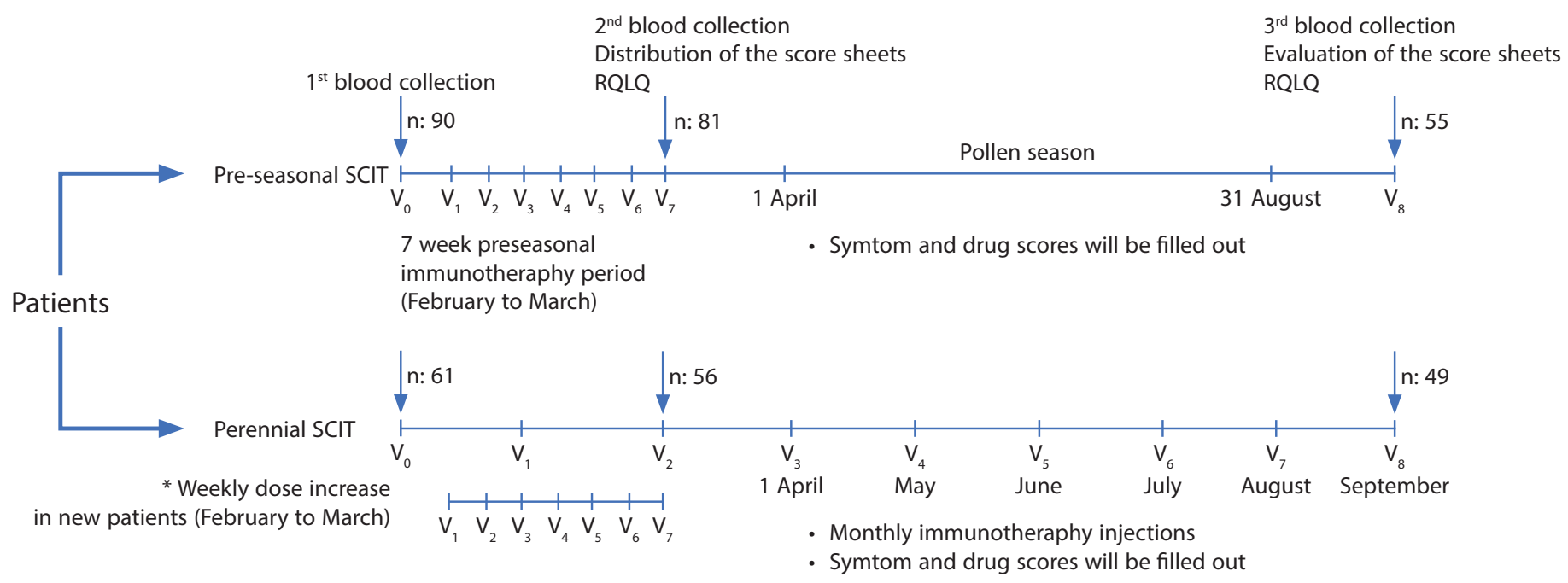

Figure 1. Study design: A prospective cross-sectional two-armed study. Preseasonal immunotherapy group and perennial immunotherapy group. Three time points were determined for the measurements: $\mathrm{V}_{0}$-before $1^{\text {st }}$ injection, $\mathrm{V}_{7}$-after $7^{\text {th }}$ injection and $\mathrm{V}_{8}$-end of pollen season. Symptom and medication scores were filled between $V_{7}$ and $V_{8}$, RQLQ was filled at $V_{7}$ and $V_{8}$. Blood were collected at three time points to measure sIgE, sIgG4, IL-10 concentrations. 


\section{Study group}

All patients who were scheduled to have preseasonal or perennial allergoid SCIT with grass and/or grass plus cereal pollens in the 2018 season were asked whether they volunteered to participate in the study. All patients except those who did not approve were included. At the time of evaluation in 2018, our study group consisted of preseasonal and perennial allergoid SCIT patients who were in their $1^{\text {st }}$, $2^{\text {nd }}, 3^{\text {rd }}, 4^{\text {th }}$ and $5^{\text {th }}$ years of immunotherapy.

Patients who underwent preseasonal immunotherapy with different allergens in different seasons, who received both preseasonal and perennial immunotherapy during the total duration of immunotherapy, who did not have regular follow-ups and regular dose escalations were excluded from the study.

\section{Immunotherapy schedules}

Immunotherapeutic product used in the both arms of the study was an aluminium hydroxide adsorbed depot allergoid, containing either grasses extracts (Velvet grass, Orchard grass, Rye grass, Timothy grass, Kentucky blue grass, Meadow fescue) (Allergovit ${ }^{\circledR}$-006, Allergopharma, Germany) or grass and cereals (Grasses, Barley, Rye, Oat, Wheat) (Allergovit ${ }^{\circledR}$-015, Allergopharma, Germany). Allergoids are chemically modified forms of the allergens with low allergenicity. ${ }^{17}$ Pollen allergoid immunotherapy kit consists of two vials: Vial A-1000 TU/ml and Vial-B-10000 TU/ml plant pollen allergoids. In preseasonal group initial treatment started in February 2018 with the lowest dosage of the lowest concentration $(0.1 \mathrm{ml}$ from concentration $\mathrm{A})$. The dosage was doubled weekly from concentration A and $\mathrm{B}$ respectively (preseasonal dose protocol; A: $0.1 \mathrm{ml}, 0.2 \mathrm{ml}, 0.4 \mathrm{ml}, 0.8 \mathrm{ml}$ then, B: $0.15 \mathrm{ml}, 0.3 \mathrm{ml}, 0.6 \mathrm{ml}$ ). After the completion of 7 injections, preseasonal immunotherapy was stopped for the 2018 season. In the perennial immunotherapy group, immunotherapy was started with preseasonal dose protocol in the $1^{\text {st }}$ year and then followed by monthly maintenence injections $(0.6 \mathrm{ml}$ from vial-B) without any interval for 5 years.

\section{Evaluation of clinical effectiveness}

All patients filled the symptom and medication scores between April 1 to August 31. Nasal (itching, sneezing, runny nose and congestion) and ocular (redness, itching, watery eyes) symptoms were scored daily according to the scale (0: no syptoms, 1: mild syptoms, 2: moderate symptoms, 3: severe symptoms). ${ }^{18}$ The mean daily symptom score was calculated. Medication scores were ranked as follows: 0: no medication, 1: antihistaminics, 2: nasal steroids. The highest score of the day was recorded as medication score. ${ }^{18}$ Combined score was obtained by the addition of symptom and medication scores. ${ }^{18}$
The quality of life was evaluated with the Turkish validation of the RQLQ in all patients. ${ }^{19}$ This questionnaire which basically includes 7 domains (activity limitation, sleep problems, non-nose/eye symptoms, practical problems, nose symptoms, eye symptoms, emotional function) and scored on a 7-point scale, was applied to the patients both on $\mathrm{V}_{7}$ and $\mathrm{V}_{8}$. Zero point corresponds good, six points indicates low quality of life. Overall RQLQ score was also calculated.

\section{Evaluation of immunological effectiveness}

Phl p sIgE, sIgG4 and IL-10 levels were measured at three time points in both study groups. Levels of $P h l p$ sIgE and sIgG4 antibodies were quantified by Phadia 100, EliA Fluoroimmunoassay method (Phadia, Uppsala, Sweden). Reference values for sIgE and sIgG4 were taken as $0.35-100$ $\mathrm{kU}_{\mathrm{A}} / \mathrm{L}$ and, 0-30 $\mathrm{mg}_{\mathrm{A}} / \mathrm{L}$, respectively. IL-10 production against $P h l p$ was measured by ELISA method according to the manufacturer's recommendations (IBL, TECAN, USA). Measurement range was taken as $0.31-200(\mathrm{pg} / \mathrm{ml})$.

\section{Pollen counts}

During the season, number of airborne grass pollen was determined by Burkard volumetric 7-day spore trap (Burkard manufacturing, England). Burkard volumetric spor trap is currently the most common method of sampling airborne pollens. Samples collected with this method are analysed by using light microscopes. The trap was placed on the roof of the building at the campus of Ankara University at an altitude of $30 \mathrm{~m}$ above ground level. Atmospheric sampling and analysis were performed according to the method described by the Spanish Aerobiological Network (REA) (Gala'n et al. 2007). The pollen counts were converted into daily average concentrations (grains $/ \mathrm{m}^{3}$ ).

\section{Statistics}

Statistical analyzes were made using SPSS version 15 software (SPSS, Chicago, III, USA). The normality of distribution was examined by visual (histogram and probability graphs) and analytical methods (Kolmogrov-Smirnov/Shapiro-Wilk tests). Descriptive statistics were calculated using the mean and standard deviation for normally distributed variables, using the median and interquartile range for non-normally distributed variables.

\section{- Comparisons between groups}

The data of patient groups receiving perennial or preseasonal SCIT in 2018 were compared with each other in terms of clinical (symptom, drug, combined scores, RQLQ) and immunological efficacy (sIgE, sIgG4, IL-10). In these comparisons, the dependent groups were composed of symptom, drug, combined scores, RQLQ, 
sIgE, sIgG4 and IL-10; and independent groups were preseasonal and perennial patient groups. Categorical data between these two independent groups were evaluated by Chi-Square test. The significance of the difference between the means in the groups with normal distribution was evaluated using the Student-T test, and the difference between the median values in the groups with abnormal distribution was evaluated by using Mann-Whitney-U or Kruskal-Wallis test.

\section{- In-Group Comparisons}

The difference between the levels of sIgE, sIgG4 and IL-10 was evaluated at three time points in the preseasonal and perennial groups by Wilcoxon sign rank test.

For $p<0.05$ for all tests performed, the results were considered statistically significant.

\section{Results}

Our study group consists of 151 patients (77 female, 74 male) with a mean age of $34.82 \pm 11.43$ years. Preseasonal and perennial SCIT groups included 90 and 61 subjects, respectively. One hundred four out of 151 patients completed all steps in three time points by coming regular visits and injections, filling scores and quality of life questionnaire and giving blood samples. Therefore, between-group and in-group comparisons were made on 104 patients (55 preseasonal group/ 49 perennial group) These two groups exhibit similar demographic characteristics (Table 1). None of the patients in both study groups suffered serious adverse reactions during the dosing schedules.

\section{Clinical effectiveness}

Patients in preseasonal SCIT group had better symptom control than patients in the perennial SCIT group for most of the weeks particularly during the peak pollen period. (April: $\mathrm{w}-2$ \& $\mathrm{w}-4, p=0.04$; May: $\mathrm{w}-2, p=0.02$; June: $\mathrm{w}-1, \mathrm{w}-2$, $p=0.02 ; \mathrm{w}-3, \mathrm{w}-5, p=0.03$; July: $\mathrm{w}-2, p=0.01 ; \mathrm{w}-3, p=0.02$; $\mathrm{w}-4, p=0.04$ ) (Figure 2) However, two groups were similar in terms of medication and combined scores.

According to the results of the quality of life questionnaire that belongs to March, patients in the preseasonal SCIT group had lower overall scores and lower scores in the domains of activity limitation, sleep problems, practical problems and eye symptoms. In September, scores of quality of life were similar in both groups (Figure 3).

Table 1. Demographic characteristics of the patients.

\begin{tabular}{|c|c|c|c|}
\hline & $\begin{array}{c}\text { Preseasonal } \\
\text { (n: } 55)\end{array}$ & $\begin{array}{l}\text { Perennial } \\
(\mathrm{n}: 49)\end{array}$ & $P$ \\
\hline Age $($ mean $\pm \mathrm{SD})$ (year) & $35.84 \pm 11.76$ & $36.53 \pm 10.72$ & 0.75 \\
\hline Gender & & & 0.89 \\
\hline Female & 33 & 30 & \\
\hline Male & 22 & 19 & \\
\hline Diagnosis & & & 0.51 \\
\hline Allergic rhinitis (AR) & 38 & 37 & \\
\hline $\mathrm{AR}+$ asthma & 17 & 12 & \\
\hline Type of allergen & & & 0.55 \\
\hline 006 (Grass polen) & 20 & 21 & \\
\hline 015 (Grass + Rye) & 35 & 28 & \\
\hline Duration of immunotherapy & & & 0.93 \\
\hline $1^{\text {st }}$ year & 8 & 8 & \\
\hline $2^{\text {nd }}$ year & 14 & 15 & \\
\hline $3^{\text {th }}$ year & 13 & 12 & \\
\hline $4^{\text {th }}$ year & 12 & 8 & \\
\hline $5^{\text {th }}$ year & 8 & 6 & \\
\hline
\end{tabular}



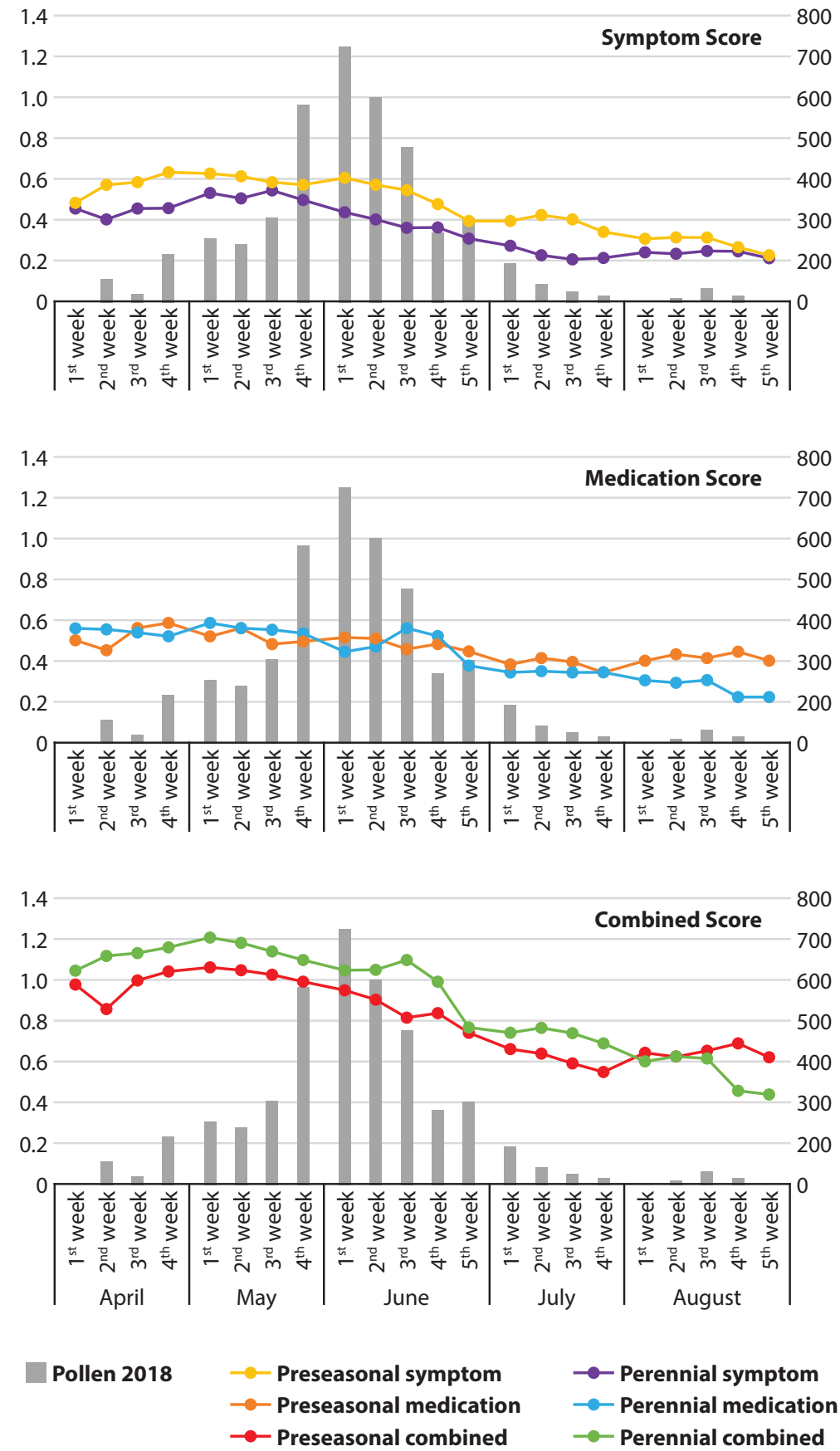

Figure 2. Weekly symptom, medication and combined scores of the patients in preseasonal and perennial SCIT groups with pollen count in 2018. In some weeks, there are differences in symptom scores between preseasonal and perennial SCIT groups. (April: $\mathrm{w}-2$ \& w-4, $p=0.04$; May: $\mathrm{w}-2, p=0.02$; June: $\mathrm{w}-1, \mathrm{w}-2, p=0.02$; $\mathrm{w}-3, \mathrm{w}-5, p=0.03$; July: $\mathrm{w}-2, p=0.01 ; \mathrm{w}-3, p=0.02$; $\mathrm{w}-4, p=0.04$ ) 


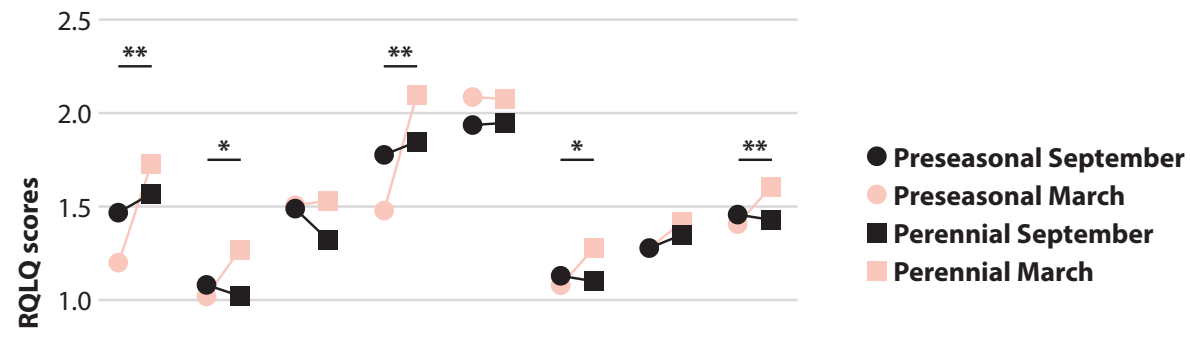

0.5

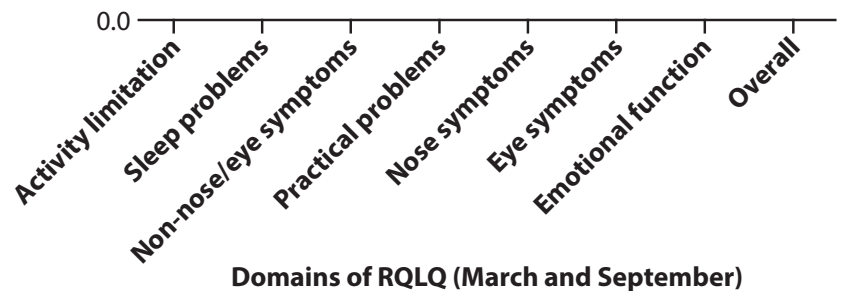

Figure 3. Change in the mean quality of life scores between March $\left(V_{7}\right)$ and September $\left(V_{8}\right)$ in preseasonal and perennial groups. March; preseasonal SCIT group had lower overall scores $(p<0.01)$ and lower scores in the domains of activity limitation $(p=0.001)$, sleep problems $(p=0.03)$, practical problems $(p=0.003)$ and eye symptoms $(p=0.01)$ than perennial SCIT group. September; scores of quality of life were similar in both groups.

\section{Immunological effectiveness}

In the preseasonal group, sIgE levels increased rapidly with the first injection and decreased after the pollen season, but did not return to basal levels $(p<0.0001)$. In the perennial SCIT group, sIgE levels were higher, and remained almost at the same level, except for the effect of the pollen season. There was no significant difference in $\operatorname{sgE}$ values between preseasonal and perennial immunotherapy groups at all three time points (Table 2) (Figure 4a).
At the end of the seventh injection, sIgG4 levels increased in all preseasonal SCIT patients and then decreased to almost basal levels $(p<0.0001)$. However, in the perennial immunotherapy group, sIgG4 levels were higher than the preseasonal immunotherapy group, especially at the first and third time points, and it was seen to be more stable in general (Table 2) (Figure 4b).

Table 2. Levels of sIgE, sIgG4 and IL-10 at three time points in preseasonal and perennial SCIT groups

\begin{tabular}{|c|c|c|c|c|}
\hline & & $\begin{array}{c}\text { Preseasonal median } \\
\text { (IQR) }\end{array}$ & $\begin{array}{c}\text { Preseasonal median } \\
\text { (IQR) }\end{array}$ & $P$ \\
\hline $\operatorname{sig} \mathrm{E}$ & Basal- $\mathrm{V}_{0}\left(\mathrm{kU}_{\mathrm{A}} / \mathrm{L}\right)$ & $1.14(3.09)$ & $1.91(6.4)$ & 0.260 \\
\hline $\operatorname{sIgE}$ & $7^{\text {th }}$ week- $\mathrm{V}_{7}\left(\mathrm{kU}_{\mathrm{A}} / \mathrm{L}\right)$ & $5.88(10.61)$ & $3.45(9.41)$ & 0.143 \\
\hline $\operatorname{sIgE}$ & September- $\mathrm{V}_{8}\left(\mathrm{kU}_{\mathrm{A}} / \mathrm{L}\right)$ & $2.21(6.33)$ & $2.71(6.66)$ & 0.992 \\
\hline sIgG4 & Basal- $\mathrm{V}_{0}\left(\mathrm{mg}_{\mathrm{A}} / \mathrm{L}\right)$ & $0.02(0.04)$ & $0.13(0.77)$ & $<0.0001$ \\
\hline sIgG4 & $7^{\text {th }}$ week- $V_{7}\left(\mathrm{mg}_{\mathrm{A}} / \mathrm{L}\right)$ & $0.52(0.94)$ & $0.33(1.06)$ & 0.691 \\
\hline sIgG4 & September- $\mathrm{V}_{8}\left(\mathrm{mg}_{\mathrm{A}} / \mathrm{L}\right)$ & $0.04(0.1)$ & $0.12(0.54)$ & $<0.0001$ \\
\hline IL-10 & Basal- $V_{0}(\mathrm{pg} / \mathrm{ml})$ & $1.45(3.48)$ & $2.03(3.67)$ & 0.528 \\
\hline IL-10 & $7^{\text {th }}$ week- $V_{7}(\mathrm{pg} / \mathrm{ml})$ & $2.29(2.36)$ & $2.19(4.16)$ & 0.902 \\
\hline IL-10 & September- $V_{8}(\mathrm{pg} / \mathrm{ml})$ & $2.32(2.95)$ & $2.16(3.73)$ & 0.909 \\
\hline
\end{tabular}




\section{A}

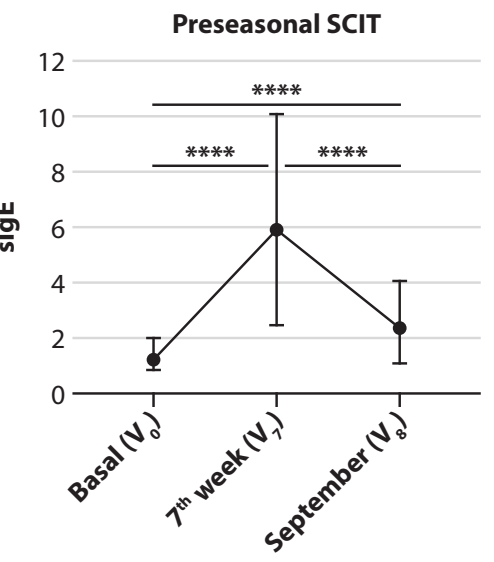

B

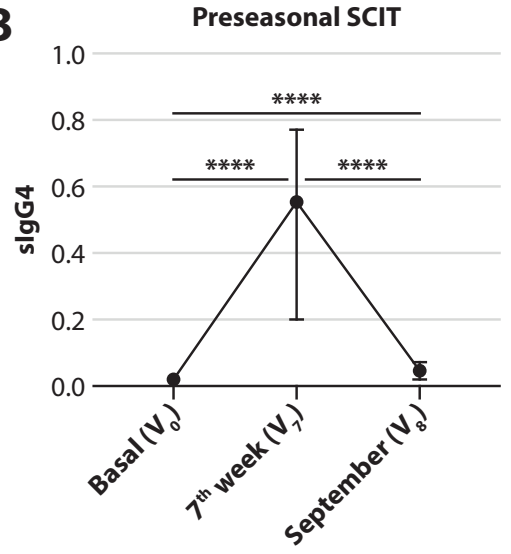

C

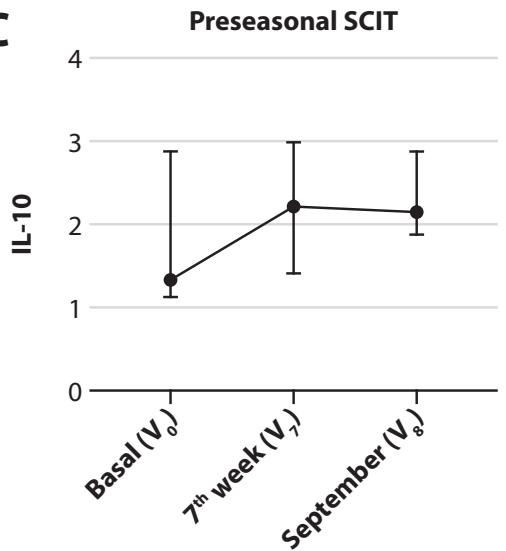

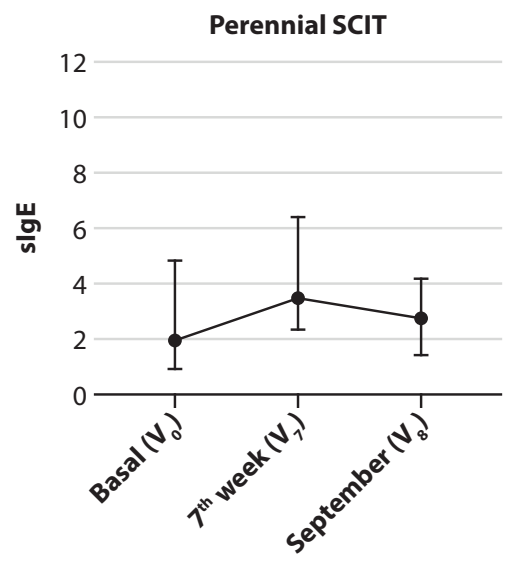
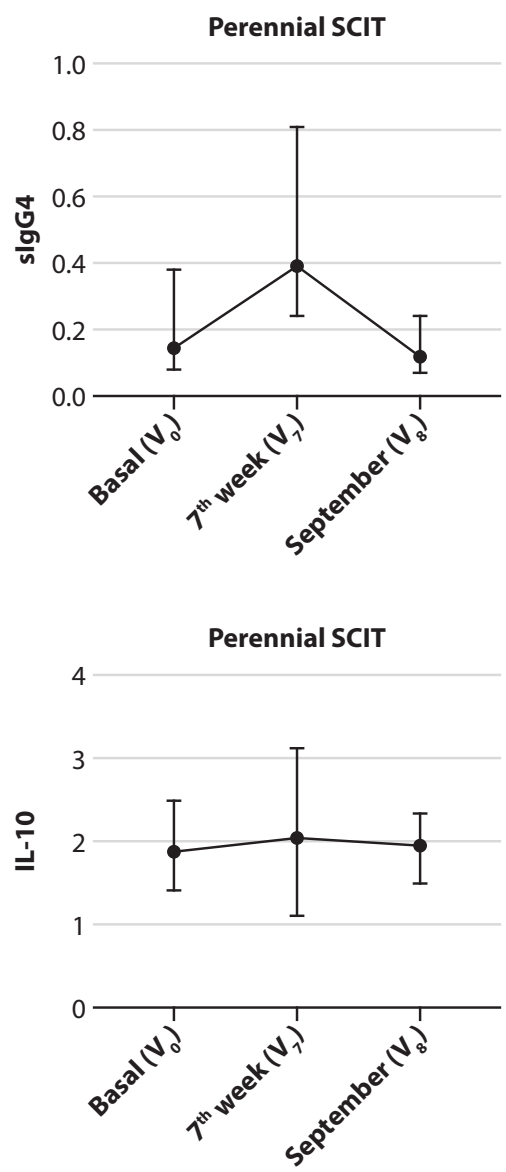

Figure 4.

A. Change in the sIgE values at three time points in preseasonal and perennial immunotherapy groups. In preseasonal group, sIgE levels were different at three time points $(p<0.0001)$.

B. Change in the sIgG4 values at three time points in preseasonal and perennial immunotherapy groups. In preseasonal group; sIgG4 levels were different at three time points $(p<0.0001)$. Between groups; sIgG4 levels were different at $\mathrm{V}_{0}$ and $\mathrm{V}_{8}$ C. Change in IL-10 values at three time points in preseasonal and perennial immunotherapy groups. $(p>0.05)$ 
IL-10 levels increased with immunotherapy injections in the preseasonal SCIT group and then maintained its level. However, in the perennial group, IL-10 was observed to be higher in basal measurement and to be more stable. (Table 2) (Figure 4c).

\section{Pollen count}

In 2018, the amount of pollen in the atmosphere was slightly higher than the previous year and it was detected one month earlier. Pollen which started to be detected in mid-March, was counted as $394 / \mathrm{m}^{3}$ in April and increased significantly by reaching 1341 pollen $/ \mathrm{m}^{3}$ count with May. It reached to $1892 \mathrm{pollen} / \mathrm{m}^{3}$ in June then dropped rapidly to 233,59 and 24 pollen $/ \mathrm{m}^{3}$ in July, August and September, respectivly and could not be detected after September.

\section{Discussion}

The results of the study showed that, preseasonal immunotherapy was more effective to control the symptoms during the pollen season. But, the quality of life was similar in both arms throughout the season. In terms of immunological efficacy, immune tolerance was induced more strongly and permanently in the perennial immunotherapy group.

Since there is no objective measurement in evaluating the effectiveness of immunotherapy, the decision is made mostly by clinical evaluation based on the daily symptom severity and the medication usage. Although there are some controversies, various studies have shown that the improvement in patients' symptom scores is correlated with changes in immunological parameters (such as increase in sIgG4 and IL-10). ${ }^{20-23}$ More specifically in most of these studies SCIT was used in patients with HDM allergy. But recently, some studies demonstrated that clinical improvement with preseasonal immunotherapy was accompanied by a significant increase in sIgG4.,16,24 In our study, allergoid immunotherapy was effective on symptoms in both groups and no increase was observed in patients' symptoms during peak pollen season. However, it was found that preseasonal immunotherapy had a better control on the symptoms for most of the weeks, particularly during the peak pollen period. In parallel with the improvement in symptoms, a rapid increase in sIgG4 and IL-10 levels were observed in the preseasonal group, but the immunological markers decreased after the pollen season. However, in the perenial group sIgG4 and IL-10 levels were always higher and remained almost at the same levels. Similar to our results, various studies have shown rapid clinical and immunological efficacy in preseasonal allergoid immunotherapy compared to placebo or perennial immunotherapy. ${ }^{8-10,16,24}$
Head-to-head comparison studies on the effectiveness of preseasonal and perennial immunotherapy are limited in the literature. Mostly, the comparison was made with the sublingual vaccines and clinical efficacy of two regimens has been found similar. ${ }^{13-15}$ In a randomized placebo-controlled study comparing preseasonal and perennial allergoid SCIT for clinical and immunological efficacy, perennial immunotherapy has been reported to be a more effective option in the treatment of allergic rhinitis. This is explained by the strong correlation between increased cumulative allergen dose and symptom control and sIgG4 levels. ${ }^{16}$ Based on our clinical assessment, we can say that preseasonal immunotherapy provides an early and strong control of symptoms, but both regimens effect the quality of life equally throughout the season. In accordance with the findings of Tworek et al., in our study group, the higher and more stable course of sIgG4 concentration in the perennial immunotherapy arm was thought to be associated with cumulative immunotherapy doses.

Regarding the mechanism of AIT, the increase in sIgG4 during AIT is most likely due to the shift of the $\mathrm{T}$ cell population from allergen-specific Th2 to Tregs and an increase in the number of Bregs. ${ }^{25-27}$ In our study, we found that there was an increase in sIgG4 levels with immunotherapy which was faster in the preseasonal immunotherapy group who received a high cumulative dose of allergen in a short term. However, in the perennial immunotherapy group who received the maintanence dose of allergen periodically for a longer time, sIgG4 levels were found to be higher and the levels were more stable throughout the observation period. In line with our results, sIgG4 levels were found to be higher in perennial SCIT group in a randomized double blind placebo controlled study. ${ }^{16}$

Allergen immunotherapy could effect and block allergen specific IgE binding on B cells. Besides, it induces the production of IL-10 from Tregs and Bregs. ${ }^{28}$ There have been several reports suggesting that IL-10, is a potent suppressor of allergen-specific IgE, and that IL-10 is also responsible for the increase in IgG4 production with Bregs. ${ }^{25,27,29-31}$ Shamji et al reported that; with grass pollen SCIT, IL- $10^{+}$Bregs and IgG4 levels are correlated and increased. ${ }^{32}$ In our study, although we found a parallel increase in IL-10 levels with IgG4; unlike the IgG4 course, we found that IL-10 levels remained quite stable in the preseasonal immunotherapy group, similarly to the perennial group.

When evaluating our results, some methodological weaknesses should be considered. Although the research has a prospective design, we followed the patients for one season and compared the two protocols of immunotheraphy. The absence of a placebo arm may have led to a more significant improvement being overlooked. In addition, lack of a direct comparison with placebo makes it difficult to predict the significance of clinical and immunological improvements. 
Furthermore, recording the scores only during the pollen season makes it difficult to interpret the changes seen in the pollen season. However, when the whole pollen season and the peak pollen period were compared, the absence of increase in scores with the pollen peak suggested that both immunotherapies were effective. In addition, the preseasonal group had lower symptom scores which suggests the advantage of preseasonal immunotherapy in symptom control with receiving high cumulative allergen dose within short period before polen season. Although all these limitations mentioned above may have reduced the strength of our results, they can be positively adapted to clinical practice when supported by randomized placebo-controlled studies in the near future.

To conclude, preseasonal immunotherapy provides better control of symptoms in a short time, while antibody response with perennial immunotherapy has been found to be more stable. This can be explained by the strong induction of antibody production with the intensive and frequent allergen dose just prior to the season in preseasonal immunotherapy, and by the high cumulative allergen dose throughout the year in the perennial immunotherapy. According to these findings, we suggest to start with preseasonal immunotherapy to achieve prominent symptom control throughout the season, followed by perennial injections to achieve a stronger immunological and clinical effect in patients with seasonal allergic rhinitis.

\section{Acknowledgements}

We thank Satı Saykan and Yelda Ateş for providing support when calculating seasonal scores and quality of life score (RQLQ). We thank Emel Eymirli for immunotherapy injections and the organization of patients.

\section{Conflict of Interest}

Authors declare that they have no conflict of interest.

\section{Funding Sources}

The study was funded by Ankara University Scientific Research Projects Office (Project No: 18B0230006).

\section{Author contributions}

- ZCS: made contributions to study design, collecting and analysis of data, performing immunological tests, manuscript drafting and revision.

- DM: made substantial contributions to the concept and design, manuscript drafting and revision.

- ÖA: made contributions to data collection and manuscript revision.

- ÖA, DS: made contributions to data collection and performing immunological test.

- MP: made the pollen count in the air.

- MP, BAS, YD: been involved in revising the manuscript.

\section{References}

1. Bousquet J, Lockey R, Malling HJ. Allergen immunotherapy: therapeutic vaccines for allergic diseases. A WHO position paper. J Allergy Clin Immunol. 1998;102(4 Pt 1):558-62.

2. Alvarez-Cuesta E, Bousquet J, Canonica GW, Durham SR, Malling HJ, Valovirta E, et al. Standards for practical allergen-specific immunotherapy. Allergy. 2006;61 Suppl 82:1-20.

3. Schmidt-Weber CB, Blaser K. New insights into the mechanisms of allergen-specific immunotherapy. Curr Opin Allergy Clin Immunol. 2005; 5(6):525-30.

4. Olivier CE. The use of allergoids and adjuvants in allergen immunotherapy. Arch Asthma Allergy Immunol. 2017;1:040-60.

5. Conrad ML, Renz H, Blaser K. Immunological approaches for tolerance induction in allergy. In: Valenta R, Coffman RL, Editors. Vaccines against Allergies. 352. Berlin, Heidelberg: Springer; 2011. p. 1-26.

6. Bousquet J, Maasch HJ, Hejjaoui A, Skassa-Brociek W, Wahl R, Dhivert $\mathrm{H}$, et al. Double-blind, placebo-controlled immunotherapy with mixed grass-pollen allergoids. III. Efficacy and safety of unfractionated and high-molecular-weight preparations in rhinoconjunctivitis and asthma. J Allergy Clin Immunol. 1989;84(4 Pt 1):546-56.

7. Distler A, Pappelendam D. 13-year overview of serious adverse drug reactions following subcutaneous specific immunotherapy with a chemically modified allergen preparation. Allergo J Int. 2015;24(8): 294-302.

8. Corrigan CJ, Kettner J, Doemer C, Cromwell O, Narkus A, Study G. Efficacy and safety of preseasonal-specific immunotherapy with an aluminium-adsorbed six-grass pollen allergoid. Allergy. 2005;60(6):801-7.

9. Rajakulasingam K. Early improvement of patients' condition during allergen-specific subcutaneous immunotherapy with a high-dose hypoallergenic 6-grass pollen preparation. Eur Ann Allergy Clin Immunol. 2012;44(3):128-34.

10. Williams A, Henzgen M, Rajakulasingam K. Additional benefit of a third year of specific grass pollen allergoid immunotherapy in patients with seasonal allergic rhinitis. Eur Ann Allergy Clin Immunol. 2007;39(4): 123-6.

11. Dominicus R. 3-years' long-term effect of subcutaneous immunotherapy (SCIT) with a high-dose hypoallergenic 6-grass pollen preparation in adults. Eur Ann Allergy Clin Immunol. 2012;44(3):135.

12. Özdemir SK, Sin BA, Güloğlu D, İkincioğulları A, Gençtürk Z, Misırligil Z. Short-term preseasonal immunotherapy: is early clinical efficacy related to the basophil response? Int Arch Allergy Immunol. 2014;164(3):237-45.

13. Quercia O, Bruno M, Compalati E, Falagiani P, Mistrello G, Stefanini G. Efficacy and safety of sublingual immunotherapy with grass monomeric allergoid: comparison between two different treatment regimens. Eur Ann Allergy Clin Immunol. 2011;43(6):176.

14. Arasi S, Pajno GB. Pre-Coseasonal vs Perennial Sublingual Immunotherapy for Seasonal Allergens Dosing Regimen: Long-Term Benefits, Adherence, and Cost-Effectiveness-Is There a Difference? Curr Treat Options Allergy. 2016;3(1):93-101.

15. Stelmach I, Kaluzinska-Parzyszek I, Jerzynska J, Stelmach P, Stelmach W, Majak P. Comparative effect of pre-coseasonal and continuous grass sublingual immunotherapy in children. Allergy. 2012;67(3):312-20.

16. Tworek D, Bochenska-Marciniak M, Kuprys-Lipinska I, Kupczyk M, Kuna P. Perennial is more effective than preseasonal subcutaneous immunotherapy in the treatment of seasonal allergic rhinoconjunctivitis. Am J Rhinol Allergy. 2013;27(4):304-8.

17. Cirkovic TD, Bukilica MN, Gavrovic MD, Vujcic ZM, Petrovic S, Jankov RM. Physicochemical and immunologic characterization of low-molecular-weight allergoids of Dactylis glomerata pollen proteins. Allergy. 1999;54(2):128-34.

18. Clark J, Schall R. Assessment of combined symptom and medication scores for rhinoconjunctivitis immunotherapy clinical trials. Allergy. 2007;62(9):1023-8.

19. Yuksel H, Yilmaz O, Alkan S, Bayrak Degirmenci P, Kirmaz C. Validity and reliability of Turkish version of rhinitis and mini-rhinitis quality of life questionnaires. Allergol Immunopathol (Madr). 2009;37(6):293-7.

20. Mungan D, Misirligil Z, Gurbuz L. Comparison of the efficacy of subcutaneous and sublingual immunotherapy in mite-sensitive patients with rhinitis and asthma--a placebo controlled study. Ann Allergy Asthma Immunol. 1999;82(5):485-90. 
21. Eifan AO, Akkoc T, Yildiz A, Keles S, Ozdemir C, Bahceciler NN, et al. Clinical efficacy and immunological mechanisms of sublingual and subcutaneous immunotherapy in asthmatic/rhinitis children sensitized to house dust mite: an open randomized controlled trial. Clin Exp Allergy. 2010;40(6):922-32.

22. Yukselen A, Kendirli SG, Yilmaz M, Altintas DU, Karakoc GB. Two year follow-up of clinical and inflammation parameters in children monosensitized to mites undergoing subcutaneous and sublingual immunotherapy. Asian Pac J Allergy Immunol. 2013;31(3):233-41.

23. Roger A, Depreux N, Jurgens Y, Serra AT, Heath MD, Garcia G, et al. A novel microcrystalline tyrosine-adsorbed, mite-allergoid subcutaneous immunotherapy: 1-year follow-up report. Immunotherapy. 2016;8(10): 1169-74.

24. Soyyigit S, Aydin O, Secil D, Dogan C, Gokmen D, Sin B, et al. Effectiveness of preseasonal allergoid immunotherapy: Controlled trial in monosensitized and polysensitized patients. European Academy of Allergy and Clinical Immunology Congress; Munich, Germany: ; 2018. p. 482-3.

25. van de Veen $\mathrm{W}$, Akdis M. Tolerance mechanisms of allergen immunotherapy. Allergy. 2020;75(5):1017-8.

26. Akdis CA, Akdis M. Mechanisms of allergen-specific immunotherapy and immune tolerance to allergens. World Allergy Organ J. 2015;8(1):17.
27. Satitsuksanoa P, van de Veen W, Akdis M. B-cell responses in allergen immunotherapy. Curr Opin Allergy Clin Immunol. 2019;19(6):632-9.

28. Ye YM, Lee SK, Kim SH, Nahm DH, Suh CH, Park HS. Changes of serum cytokines after the long term immunotherapy with Japanese hop pollen extracts. J Korean Med Sci. 2006;21(5):805-10.

29. van de Veen W, Stanic B, Wirz OF, Jansen K, Globinska A, Akdis M. Role of regulatory B cells in immune tolerance to allergens and beyond. J Allergy Clin Immunol. 2016;138(3):654-65.

30. Wachholz PA, Soni NK, Till SJ, Durham SR. Inhibition of allergen-IgE binding to $\mathrm{B}$ cells by IgG antibodies after grass pollen immunotherapy. J Allergy Clin Immunol. 2003;112(5):915-22.

31. Roger A, Depreux N, Jurgens Y, Heath MD, Garcia G, Skinner MA. A novel and well tolerated mite allergoid subcutaneous immunotherapy: evidence of clinical and immunologic efficacy. Immun Inflamm Dis. 2014;2(2):92-8

32. Shamji MH, Kappen J, Abubakar-Waziri H, Zhang J, Steveling E Watchman S, et al. Nasal allergen-neutralizing IgG4 antibodies block IgE-mediated responses: Novel biomarker of subcutaneous grass pollen immunotherapy. J Allergy Clin Immunol. 2019;143(3):1067-76. 